\title{
Gelar "Al-Sahid" Pada Beberapa Nisan Makam Kuna Di Indonesia (Sebuah Interpretasi Baru)
}

nfn. Mujib

Keywords: tombs, comparison, islam, typology, inscription

\section{How to Cite:}

Mujib, nfn. Gelar "Al-Sahid" Pada Beberapa Nisan Makam Kuna Di Indonesia (Sebuah Interpretasi Baru). Berkala Arkeologi, 15(1), 33-45. https:// doi.org/10.30883/jba.v15i1.653

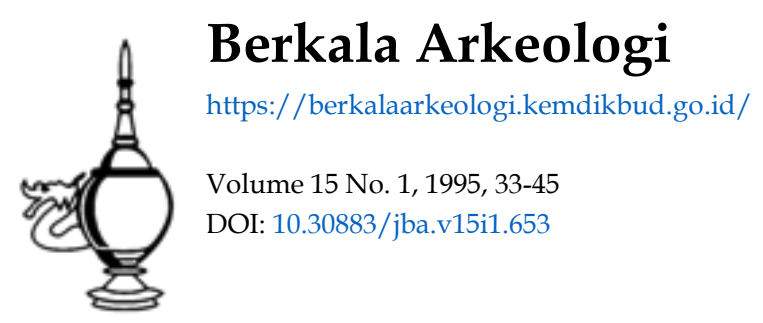

This work is licensed under a Creative Commons Attribution-NonCommercial-ShareAlike 4.0 International License. 


\title{
GELAR "AL-SAHID" PADA BEBERAPA NISAN MAKAM KUNA DI INDONESIA (Sebuah Interpretasi Baru)
}

\author{
Mujl b \\ (Balai Arkeologi Palembang)
}

\section{Pendahuluan}

Tiga nisan makam kuna, yaitu nisan makam Fatimah binti Maymun di Leran, Gresik, Jawa Timur berangka tahun 475 H (1082 M), nisan ma-kam Sultan Al-Malik Al-Salih berangka tahun 726 H (1326 M) dan nisan makam ratu Nah-risah binti Sultan Al-'Abidin berangka tahun $831 \mathrm{H}(1428 \mathrm{M}$ ) juga salah seorang keturunan Sultan Al-Malik Al-Salih di Samudera Pasai, Aceh Utara, mempunyai kekhususan tersendiri. Bila dibandingkan dengan nisannisan makam kuna lain yang pernah ditemukan dan diteliti di Indonesia yang mencapai ratusan, bahkan ribuan jumlahnya. Kekhu-susan itu tampak pada bentuk nisan, gaya inskripsi dan pemakaian laqb (gelar, abnome) yang dicerminkan adanya pengaruh Islam, dengan pe-makaian gelar Al-Sahid di depan nama-nama tersebut.

Huruf arab yang dituliskan pada nisan makam Fatimah bint Maymun bergaya Kufi, lebih spesifik lagi Kufi al-Muwarraq (berhias daun dan berfloral). Tulisan jenis ini mulai dikenal pada abad ke-4 dan $5 \mathrm{H}$, (11 dan 12 $\mathrm{M})$. Pendapat para ahli mengatakan nisan makam ini dibuat berselang 1 atau 2 abad setelah tahun wafatnya sebagaimana tertera dalm inskripsi itu, mengingat pertumbuhan tulisan jenis ini baru muncul pada abad 11 - $12 \mathrm{M}$. Jenis tulisan pada nisan makam al-Malik al-Zahir adalah Tsulus. Menurut catatan Ambari, karena pahatannya amat kasar, maka diperkira-kan nisan makam ini adalah pengganti nisan asli yang diduga hilang. Tu-lisan pada pada nisan Sultanat Nahrisahjuga bergaya Kufi, demikian ke-simpulan yang didapat penulis dari penelitian-penelitian terdahulu. Kalau diteliti dengan seksama, tidak seluruh inskripsi yang terdapat pada nisan makam Nahrisah itu bergaya Kufi, namun yang paling dominan bergaya Tsulus.

\footnotetext{
Makalah ini saya hadiahkan kepada ananda Ahmad Fananiy Rizkiansyah yang pada tanggal 30 Juni 1995 berulang-tahun ke-4. Semoga Allah SWT, menja-dikannya anak yang salih yang selalu mendo'akan kebaikan bagi kedua orang tuanya, memberinya banyak rizki yang bermanfaat bagi dirinya di dunia dan di akhirat, Amin.
} 
Tulisan yang bergaya Kufi hanya terdapat pada kalimat Basmalah saja. Jenis Kufi yang ada adalah Kufi al-Mudaffar (berkepang). Jenis tu-lisan muncul pada abad ke-6 H (12 M), saat Armenia takluk pada kekua-saan kaum Saljuk.

Ketiga nisan makam itu memuat tulisan (inskripsi) berhuruf dan berbahasa Arab yang mengandung unsur-unsur nama, gelar, tanggal, hari dan tahun wafat tokoh yang dimakamkan. Itu sebabnya, mengapa nisan makam kuna berinskrip si itu juga disebut prasasti (Buchari,1977:2). Ada juga perbedaan materi tulisan nya, yaitu dua buah nisan makam pertama dan ketiga memuat tulisan berupa ayat-ayat Al-Qur'an al-Karim, Sahadat, Do'a, sedangkan nisan yang kedua tidak memuat tulisan serupa.

Menarik untuk dikaji, ketiga nisan makam kuna tersebut mempunyai persamaan yang tidak didapatkan pada nisan-nisan makam kuna lain, berupa pemakain laqb "al-sahid" Bedanya, nisan pertama dan kedua laqb itu melekat pada nama tokoh yang dimakamkan, sedangkan pada nisan ketiga, laqb tersebut melekat pada nama tokoh yang menurunkan tokoh yang dimakamkan itu.

Lebih jelasnya, tulisan pada nisan makam pertama dapat dibaca: "Hadzihi qabr al-sahidat Fatimah binti Maymun ibn Hubat Allah" (Ini adalah kuburan "al-sahidat" Fatimah, puteri Maymun, putera Hubbat Allah).

Dan tulisan pada nisan makam kedua dapat dibaca:

"Hada qabr al-sahid al-marhum al-sultan al-Malik al-zahid sams al-dunya wa al-din Muhammad ibn Malik al-salih". (Ini adalah kuburan al-sahid lagi dihormati, Sultan al-Mali al-Zahir (raja yang kondang), penerang dunia dan agama, Mu-hammad putera Malik al-Salih).

Sedangkan tulisan pada nisan makam ketiga dapat dibaca:

"Hadihi al-muqid al-munawwar al-mutahhar al-malikat al-mu'azzamat almarhumat al-magfurat nahrisah al-mulaqqabat birabipasa xan dewi bint

Para peneliti terdahulu membaca nama ini dengan Hibat Allah. Oleh karena nama ini berasal dari Bahasa Arab, maka seharusnya nama itu dibaca sesuai dengan kaidah bahasa tersebut. Penulis membaca nama ini adalah Hubat Allah (Lihat Louis Ma'luf, 1973: 114).

2 Pada laporan yang terdahulu, kata ini dibaca berbangsa, suatu hal yang mustahil adanya. Oleh karena kalimat yang dipergunakan dalam penulisan ini seluruhnya berbahasa Arab dan kata in didahului oleh kata al-Mulaqqabat yang 
al-Sultan al-sahid (al-hidayat) al-said ibn al-'abidin ibn al-sultan Ahmad ibnal-sultan Mu-hammad ibn al-malik al-salih". (Ini adalah rumah batu yang bersinar lagi suci ratu yang dipertuan agung, dihormati lagi diampuni dosa-dosanya Nahrisah yang bergelar Rabipasa xan, Dewi puteri sultan alSahid (al-hidayah) yang mulia putera al-Abidin bidin putera sultan Ahmad putera sultan Muhammad putera al-Malik al-Salih).

Tokoh-tokoh yang namanya tercantum pada nisan makam-makam kuna dan bergelar al-sahid itu adalah Fatimah bint Maymun, Muhammad ibn al-Malik al-Salih yang bergelar al-Malik al-Zahir serta Sultan al-Hida-yat ibn Abidin ibn Sultan Ahmad ibn al-sultan muhammad ibn al-malik al-salih.

Pemakaian gelar al-sahid pada ketiga nisan makam itu kiranya patut mendapatkan perhatian dan kajian lebih seksama. Mengapa masa itu masyarakat Islam memberi gelar "al-sahid" kepada ketiga tokoh tersebut, mengingat gelar semacam itu tidak mungkin diberikan kepada semua orang, kecuali kepada orang-orang tertentu saja.

Untuk mencari jawaban, mengapa ketiga tokoh yang namanya tercantum dalam inskripsi pada nisan-nisan makamnya itu digelari al-sahid, marilah kita telusuri masalah-masalah sebagai berikut:

1. Arti dan pengertian al-sahid.

2. Latar belakang kehidupan para tokoh yang mendapatkan gelar al-sahid pada ketiga nisan makam dimaksud, berikut jasa-jasa mereka terhadap Islam sewaktu hidup.

3. Bagaimanakah tradisi penghormatan dengan pemakain gelar melalui tulisan pada nisan makam kuna.

\section{Arti dan pengertian Al-Sahid}

Kàta "al-sahid" (untuk masculin, untuk feminim, kata itu ditambah " $\mathrm{t}$ " menjadi "al-sahidat" adalah sebuah pecahan kata dari bahasa Arab "sahida" yang berarti menyaksikan. Kata al-sahid berarti kesaksian. Secara istilah, kata "sahid" dapat didefinisikan orang yang mati terbunuh (gugur) dalam berjuang fi sabilillah (di jalan Allah)" (Ibrahim Anis dkk, -: 497).

berarti bergelar..., maka kalau diteruskan dengan kata berbangsa akan didapatkan susunan kalimat: bergelar berbangsa. Sedang kata al-Mulaqqabah dalam setiap susunan harus diikuti oleh kata dengan ... dan kata dengan itu adalah huruf bi yang terdapat pada sebelum huruf $r$ - setelah al-Mulaqqabat itu. Dengan demikian, maka percampuran antara Bahasa Arab dengan Bahasa Melayu di sini adalah suatu hal yang tidak mungkin. 
Sedang fi sabilillah ${ }^{3}$ berarti "jalan Allah" (agama), jihad, haji serta mencari ilmu. Sabilillah biasanya diberi pengertian "segala bentuk kebajikan yang diperintahkan Allah kepada manusia" (Ibrahim dkk:415). Dari uraian tersebut di atas dapat dipertegas bahwa pengertian orang yang mati sahid itu ialah orang yang mati terbunuh (gugur) dalam berjuang membela aga-ma (di jalan Allah), baik karena perang, haji, mencari ilmu atau melaksa-nakan kebajikan yang diperintahkan oleh Allah.

Orang yang mati sahid demi membela agama Allah, kepadanya dijanjikan oleh-Nya:"Akan dibebaskan dari 'azab (siksa) yang pedih dan akan diampuni segala dosanya serta akan dimasukkan kedalam surga. Jika ia berjihad (berjuang) tetapi tidak gugur, maka ia dijanjikan oleh Al-lah akan mendapatkan pertolongan yang dekat vian gilang gemilang, pu-lang kerumah membawa pahala dan ganimah (harta rampasan perang)".

Keuntungan lain menurut hadis nabi SAW"Keuntungan bagi orang yang mati sahid diampuni dosa-dosanya, pada saat pertama kali darahnya mengucur dari tubuhnya, mengetahui tempat kedudukannya di sur-ga, dibebaskan dari siksa kubur, dilindungi dari rasa takut yang besar di hari kiamat dan diberi mahkota di kepalanya, disediakan 72 bidadari ser-ta dapat menanggung syafaat (pertolongan) 70 orang dari keluarganya. ${ }^{5}$

Memperhatikan pengertian dan keterangan lain tentang al-sahid dan dihubungkan orang yang sudah mati, maka kesan yang timbul dari pemberian gelar al-sahid kepada ketiga tokoh tersebut yaitu, mereka adalah para pejuang yang gugur di medan laga, karena membela agama Allah, atau sebab lain, sedang mereka dalam keadaan taat kepada Allah SWT. Pernyataan ini dapat dijadikan sebagai suatu hipotesa.

\section{Latar Belakang Kehidupan Tokoh-tokoh yang diberi gelar al- sahid.}

Inskripsi yang terdapat pada ketiga nisan makam ini, sedikit banyak telah memberikan sumbangan informasi yang berguna bagi kepentingan penelitian arkeologi dan sejarah perkembangan Islam di Indonesia. Infor-

Sayyid Sabiq dalam buku Fiqh sunnah, III, halaman 40 menerangkan, bahwa pengertian sabilillah adalah: selalu mentaati allah (melaksanakan segala perintahnya dan menjauhi segala larangannya).

${ }^{4}$ Lihat Al-Qur'a al-Karim, Surat al-Saff, ayat $10-13$.

'Hadis dar Al-Miqdad ibn Mu'diyyi Karb, diriwayatkan oleh AI-Tirmidiy dan Ibn Majah (Lihat Irsad al-'Ibad, terj. Salim AI-Bahresi, hal 683). 
masi dari hasil pembacaan inskripsi itu dapat dijadikan data utama ataupun pembanding terhadap isi naskah-naskah kuna yang pernah di temu-kan di Indonesia, baik yang berupa hikayat, tambo maupun babad.

Tidak semua tokoh yang dimakamkan, dengan nisan berinskripsi itu, ditemukan pula kisah kehidupan dalam naskah-naskah kuna. Fatimah bint Maymun ibn Hubat Allah misalnya, nama ini tidak pernah ditemukan dan tidak pula tertera dalam naskah-naskah kuna, baik yang berupa ba-bad, tambo ataupun hikayat. Hal ini menyulitkan para peneliti untuk megngetahui dengan rinci latar belakang kehidupannya. Data megenai dirinya ditemukan sebatas pada inskripsi yang terdapat pada batu nisannya yang ditemukan di Leran, Gresik, Jawa Timur, kini keadaanya memprehatinkkan, sebab inskripsi yang ada sudah aus (R.Soekmono,1994:42) karena termakan usia.

Penulisan arkeologi dan sejarah perkembangan Islam Indonesia tidak pernah menguraikan mengenai kehidupan Fatimah bint Maymun secara rinci. Hal tersebut karena data yang diperoleh berupa informasi yang terkandung dalam inskripsi batu nisan. Perkiraan yang selama ini ada adalah masa sebelum abad ke-11 $\mathrm{M}$, di Jawa Timur pernah terbentuk permukiman orang-orang Islam. Alasan yang dikemukakan ialah pedagang-pedagang Islam jarang sekali membawa keluarga mereka dalam perjalanan yang jauh untuk berdagang. Kalau mereka tinggal di suatu tempat agak lama, mereka kawin dengan perempuan pribumi, sesudah mengislamkan mereka. Tetapi wanita yang kuburannya ditemukan di Leran itu pastilah bukan muallaf (yang baru masuk Islam). Nama ayah dan datuknya juga tercantum pada batu nisan itu. (S.Q. Fatimi, 1963:39). Uka Tjandrasasmita megemukakan; bahwa Fatimah bint Maymun adalah keturunan dari Muhammad Rasul-Allah, kawin dengan pedagang kaya dari Persia yang telah lama bermukim di Jawa Timur (Tjandrasasmita, 1976:119-126). Tidak diketahui apa dasar pendapatnya itu, sejauh ini belum diketahui nama suaminya, ${ }^{6}$ la disebut juga puteri Leran atau Puteri Dewi Swara yang meninggal pada tanggal 7 Rajab 475 H (1082 M) (De Graaf dan Pigeaud, 1985:21).

Wanita-waita arab yang sudah menikah, tidak biasa menyebut nama suami di belakang namanya, seperti nama Aisah, karena suaminya bernama Muad ibn Jabal. Hal ini sesuai dengan larangan Rasulullah Muhammad SAW, untuk menghindarkan kerancuan dan kesulitanpenelusuran nasab (keturunan), (Mujib. 1992:5 dan bandingkan pula dengan al-Qur'an, surat Al- Ahzab, ayat : 5). 
Lain halnya dengan Sultan Muhammad al-Malik al-Zahir yang berkuasa di Samudera Pasai, ketika dikunjungi oleh Ibnu Batutah sekitar tahun 1345. Selain riwayatnya ditemukan pada inskripsi batunisannya, ia juga banyak dibicarakan dalam naskah kuna, seperti Hikayat Raja-raja Pasai dan Sejarah Melayu, sehingga informasi tentang latar belakang kehidupannya diketahui.

Sultan Muhammad al-Malik al-Zahir adalah putera tertua dari Sultan al-Malik al-Salih dan ibu puteri Ganggang dari Perlak, (Hill,1960), ia be narbenar bergaya seorang raja Islam, dan batas kerajaannya meluas hingga membutuhkan beberapa hari untuk menyusuri sepanjang pantai-nya. Dia seorang muslim yang saleh dan ortodoks, senang mengadakan tukar fikiran dengan ahli-ahli fikih, ushul dan istananya ramai dikunjungi oleh para tokoh ahli hukum yang datang dari Persia disamping seorang yang terpandang yang menjadi duta kerajaan ini di Delhi. Hal ini telah menunjukkan adanya hubungan antara Sumatera dengan berbagai dunia Islam. AlMalik al-Zahir adalah juga seorang jenderal yang besar yang melancarkan peperangan dengan negeri-negeri penyembah berhala seki tarnya, sehingga mereka tunduk kepadanya dan membayar upeti (Tho mas W.Arnold,1985:321). Beliau wafat karena sakit dan dimakamkan di dekat masjid Pasai (Munsji, 1963:73).

Dari informasi itu, kita dapat diketahui la adalah seorang sultan yang berjuang demi menegakkan kalimat Allah dan demi perkembangan Is-lam. Sama halnya dengan Fatimah bint Maymun, Sulatan al-Hidayat ibn Zain alAbidin ibn Sultan Ahmad ibn Sultan Muhammad al-Malik al-Zahir, latar belakang hidupnya kurang jelas. Menurut Halina yang mengutip pen dapat Ambary, la bergelar al-Malik al-Adil (Halina,1993/1994). Dari gelar-nya itu kemungkinan la adalah seorang sultan yang adil dalam memerin tah Kesultanan Pasai. Riwayat hidup sultan ini tidak jelas benar, kecuali dari pembacaan nisan makam Sultanat Nahrisah yang terdapat di Pasai. Tetapi Ambary memberikan keterangan, la adalah sultan yang memerin tah di Pasai sebelum Sultanat Nahrisah, penguasa terakhir di Kesultan an Pasai (Halina,1993/1994). Tidak diketahui kapan dia memerintah di Pasai. Kemungkinan la adalah sultan Pasai yang pernah melakukan pe perangan sampai dua kali dengan kerajaan Aru (Haru Rou) sebagaima-na yang terdapat pada sejarah Melayu, bab 24. la juga yang memerintah sewaktu Syaikh Ismail, seorang mubaligh yang menyebarkan Islam di Sumatera 
pada tahun $1414 \mathrm{M}$, sehingga berhasil mengislamkan raja Aru itu (Thomas W. Arnold, 1985 322).

\section{Pemakaian Gelar al-sahid pada Inskripsi Batu Nisan Makam dan Tradisi Penghormatan Masyarakat pada Para Leluhur di kalangan Elite}

Banyak cara yang dilakukan oleh masyarakat Indonesia dalam memberikan penghormatan kepada orang yang sudah meninggal baik yang berupa upacara ritual keagamaan atau upacara-upacara tradisi lainnya yang diwarisi dari generasi ke generasi yang berasal dari tradisi pra-Islam, namun sampai kini masih mewarnai kehidupan masyarakat Islam Indonesia.

Tradisi penghormatan masyarakat terhadap orang yang telah meninggal dituangkan melalui bentuk-bentuk upacara ritual. Upacara ritual tersebut seperti mendo'akan si mati agar diampuni segala dosanya dan diterima amal ibadahnya serta ditempakan di tempat yang layak di sisiNya, melalui upacara-upacara adat yang diwarisi dari tradisi pra Islam. Tradisi yang telah berurat berakar di kalangan masyarakat Indonesia, seperti upacara Usung nisan dan Nyadran, melalui bentuk-bentuk bangunan di atas kuburnya berupa jirat, nisan, cungkup dan aksesori lain yang terdapat pada bangunan-bangunan tersebut. Aksesoris baik berupa tulis-antulisan, ukiran-ukiran dan ujud fisik bangunan merupakan sebagian pengejawantahan ungkapan mikul duwur mendem jero dalam masyarakat Jawa.

Bukan hanya ketiga cara di atas, penghormatan masyarakat kepada si mati diwujudkan dalam bentuk tulisan pada nisan, jirat atau yang lain berupa untaian kata atau kalimat, baik berupa do'a, ayat-ayat al-Qur'an dan hadis nabi serta apa saja yang dianggapnya dapat menjadi sarana mengungkapkan emosinya untuk menyambung do'a bagi si mati agar diringankan bebannya dalam mengarungi kehidupannya di alam bakanya. Penghormatan berupa penulisan kata atau kalimat nama, saat, hari, bu-lan dan tahun meninggalnya, kadang-kadang ditambahkan laqb (gelar abnome) yang disesuaikan dengan keadaan, situasi atau amal perbuatan dan perjuangan sewaktu hidup, seperti al-sahid (orang yang mati sahid). Pada awalnya dimaksudkan agar menjadi peringatan bagi orang-orang yang masih hidup agar dapat megenang jasa si mati dan selalu ingat dirinya juga akan mengalami hal yang sama dengan orang yang telah dimakamkan itu. 
Mati sahid, bukan hanya disebabkan karena seseorang terbunuh (gugur) di medan laga, lantaran membela dan memperjuangkan agama Allah seperti pandangan masyarakat pada umumnya, namun juga sebab lain, seperti gugur dalam melaksanakan ibadah haji, menuntut ilmu, karena taat serta tabah dalam menjalankan perintah Allah SWT serta sebabsebab lain seperti yang diterangkan oleh Muhammad Rasulullah melalui hadisnya. Beliau menerangkan masalah sahid ini, sebagaimana diriwayatkan oleh Jabir ibn 'Atiq:Bahwa nabi SAW, bersabda: "Kecuali terbunuh (gugur) dalam perjuangan di jalan Allah, mati sahid itu ada tujuh, yaitu; orang yang mati karena terserang wabah penyakit menular, ${ }^{7}$ mati sahid, orang yang mati karena tenggelam, mati sahid, orang yang mati karena sakit rusuk (asma) ${ }^{8}$, mati sahid, orang yang mati karena sakit perut, mati sahid, orang yang mati karena luka yang parah sebab penyakit atau yang lain, mati sahid, orang yang mati sebab bencana alam, mati sahid dan orang yang mati karena melahirkan, mati sahid".(Sayyid Sabiq,III:39).

Kemudian nabi SAW, menerangkan masalah mati sahid ini dengan berdialog dengan sahabat-sahabatnya, seperti dari Abi Hurairah yang diriwayatkan oleh Muslim: "Bahwa nabi SAW, bertanya kepada para sahabat "apakah kalian sudah mengetahui siapakah orang yang mati sahid itu," para sahabat menjawab, Wahai Rasulullah, barang siapa yang terbunuh (gugur) di jalan allah adalah mati sahid. Rasulullah berkata: "Jika begitu, alangkah sedikitnya umatku yang mati sahid". Mereka bertanya: Jadi siapakah sebenarnya mereka yang mati sahid itu ?, Rasulullah menjawab: "Barang siapa yang terbunuh (gugur) di jalan Allah, mati sahid, barang siapa yang mati dijalan Allah (dalam keadaan taat kepada-Nya), mati sahid, barang siapa yang mati karena terjangkit penyakit menular yang ganas, mati sahid, barang siapa yang mati kafena sakit perut, mati sahid, barang siapa yang mati karena tenggelam, mati sahid" (Sayyid Sa-biq, -: 39-40).

Rasulullah menambahkan pula dalam hadis yang dikeluarkan oleh Said ibn Zaid yang diriwayatkan oleh Ahmad dan Tirmidiy: "Bahwa Nabi SAW bersabda, barang siapa gugur dalam mempeertahankan harta ben-

Diterjemahkan dari kata ta'un, artinya wabah penyakit menular yang disebabkan karena tikus. Dapat diduga bahwa penyakit ini adalah sebangsa penyakit pes (Lihat: Louis Ma'luf: 466; Ibrahim Anis, III:558).

${ }^{8}$ Ini diterjemahkan dari Dat al-Janb, dapat diterjemahkan sakit yangmenimpa rusuk manusia yang dapat menimbulkan demam dan batuk. 
danya, mati sahid, barang siapa yang gugur dalam mempertahankan darahnya (martabat-nya), mati sahid, barang siapa yang gugur dalam membela keluarganya, mati sahid (Sayyid Sabiq, - 40). ${ }^{9}$

Dihubungkan ketiga tokoh yang namanya tercantum dalam batu nisan makamnya, laqb al-sahid mempunyai pengertian yang berbeda. Kecuali Sul-tan Muhammad al-Malik al-Zahir, tokoh-tokoh yang tersebut di atas tidak banyak diketahui latar belakang kehidupannya, sehingga sulit untuk menentukan termasuk golongan mati sahid. Paling tidak, misalnya al-Malik al-Zahir diketahui kesahidannya bukan lantaran dia gugur di medan laga dalam rang-ka memperjuangkan agama Allah, melainkan dia termasuk man mata fi sabilillah (orang mati dalam keadaan taat kepada Allah, dengan selalu mengerjakan perintah dan menjauhi larangan-Nya), gelar itu diberikan oleh masyarakat sebagai penghargaan kepadanya karena ia berhasil mengembangkan agama Islam dan kuatnya menghidupkembangkan diskusi keagamaan.

Latar belakang kehidupan Fatimah bint Maymun tidak banyak diketahui, sehingga tingkat kesahidannyapun hanya dapat diperkirakan. Kemungkinan la adalah seorang pemberani, karena dalam kondisi masyarakat yang hinduistik waktu itu, walaupun ia seorang wanita berani berda'wah ke jalan Allah, yang mengingatkan kepada kita Khadijah, isteri Rasulullah, Muhammad SAW, yang berhasil mendampingi suaminya dalam berda'wah menyebarkan agama Islam.

Kemungkinan, tingkat kesahidannya diperoleh berkat perjuangannya dalam da'wah Islam dan bukan karena gugur di medan laga dalam perjuangan, mengingat tidak satupun peperangan yang melibatkan orangorang Islam dengan orang-orang yang tidak menyukainya yang tertoreh dalam sejarah masa lalu, abad $11 \mathrm{M}$. Ini dikuatkan dengan kondisi dan jumlah umat Islam kala ita yang diduga masih sedikit. Oleh karena itu mereka tidak mungkin melawan arus, menentang penguasa kerajaan kahuripan, dan sesuai pula dengan sistem da'wah Islam di Indonesia yang secara damai itu. Bukankah Islam datang ke Indonesia dengan cara damai.

9 Seluruh yang diterangkan di atas adalah khusus bagi orang-arang yang mempercayai dan mengamalkan ajaran Muhammad SAW, serfa selalu bertaqwa, menjalankan perintah dan menjauhi larangan Allah SWT. 
Sedangkan al-Malik al-Adil, indikasi kesahidannya diperoleh karena ia gugur di medan laga dalam melawan serbuan tentara kerajaan Aru (Haru, Rao) ke Pasai. Penyerangan ini terjadi karena kesalahpahaman antara tentara Pasai dengan tentara Aru mengenai surat yang dikirim oleh Raja Aru kepada Sultan Pasai. Pendapat ini baru sementara, me-ngingat studi ini harus dilakukan lagi terhadap naskah-naskah kuna yang ada dan belum adanya bukti yang lebih valid ditemukan.

Hal yang penting, pemberian gelar sahid dilakukan oleh masyarakat kepada leluhur mereka yang pernah berjasa dalam penyebaran Islam, baik raja maupun ulama. Gelar al-sahid memberikan indikasi bahwa na-manama di atasnya mati sahid, selain itu merupakan penghormatan bagi mereka, karena mereka dianggap berjasa pada masyarakat terutama dalam pengembangan agama Islam. Jadi gelar al-sahid itu disamping mempunyai kaitan dengan kondisi dan kenyataan dengan si mati, juga merupakan penghargaan yang diberikan masyarakat kepada mereka.

\section{Penutup}

Gelar al-sahid yang ditemukan pada inskripsi tiga buah nisan makam; Fatimah bint Maymun, Sultan al-Hidayah ibn Sultan Zain al-abidin ibn sultan ahmad inb sultan al-Malik al-Zahir mempunyai kaitan dengan perjuangan hidup tokoh yang namanya ditemukan gelar al-sahid itu. Namun tingkat kesahidan mereka berbeda antara satu dengan lainnya, mengingat sepak terjang kehidupan mereka dan perjuangannyapun berbeda pula.

Fatimah bint Maymun, diduga mendapat gelar al-sahid berkat keberaniannya, berjuang demi mengembangkan agama Islam, sekalipun ia seorang wanita. Namun ia berani mengembara (mengikuti suaminya) berdagang sambil berda'wah menyiarkan agama Islam di masyarakat yang mayoritas beragama Hindu.

Sultan al-Malik al-Zahir, mendapat gelar al-sahid berkat perjuangannya dalam mengembangkan keilmuan dalam Islam, bukan karena ia terbunuh (gugur) di medan laga. Sedangkan Sultan al-Hidayah, al-Malik alAdil, mendapat gelar al-sahid karena ia berhasil mempertahankan Kesultanan Pasai dari gempuran tentara kerajaan Aru yang menyerangnya sampai dua kali ke Pasai. 
Uraian tersebut di atas dapat disimpulankan bahwa gelar al-sahid diberikan oleh masyarakat kepada para leluhur yang dianggap berjasa kepada mereka, terutama dalam mengembangkan agama Islam.

\section{KEPUSTAKAAN}

\section{Al-Qur'an al-Karim.}

Al-Baba,1992.Kamil, Dinamika Kaligrafi Islam, Terjemahan D. Sirodjuddin, Darul-Ulum Press, Jakarta.

Al-Bahresi, Salim, Irsyadul-'Ibad, Surabaya: Salim Nabhan.

Al-Sabuni, Muhammad Ali, Tafsir ayat al-Ahkam II, Beirut: Dar al-Fikr.

Al-Sa'rawiy, Al-Syekh Muhammad Mutawalliy,Al-Mukhtar min Tafsir alQur'an al-'Adzim, Maktabah al-Turats al-Islamiy, Kairo.

Ambary, Hasan Mu'arif, 1987. Awal Masuknya Islam di Indonesia dan Pertumbuhannya Hingga Abad ke-18 M, 10 Tahun Kerjasama Pusat Penelitian Arkeologi Nasional dan EFEO, Pusat Penelitian Arkeologi Nasional, Jakarta.

1987. Ringkasan Desertasi: L 'Art Funeraire Musulman en Indonesia des Origines Aux xix emen Siecle, 10 Tahun Kerjasama Puslit Arkenas dengan EFEO Jakarta:Puslit Arkenas.

1991. Kaligrafi Islam Indonesia Dan Signifikansinya Dari Kajian Arkeologi, Pidato Pengukuhan Jabatan ahll Peneliti Utama Pada Pusat Penelitian Arkeologi Nasional, Jakarta.

1991. Makam-Makam Kesultanan dan Para wali Penyebar Islam di Pulau Jawa, Aspek-Aspek Arkeologi Indonesia, no. 12, Pusat Penelitian Arkeologi Nasional, Jakarta. 
Anis, Ibrahim, Al-Mu'jam al-Wasit I, Beirut, Dar al-Fikr.

Arnold,Thomas W.1985.Sejarah Da'wah Islam Terjemahan A. Nawai Rambe Wijaya, Jakarta.

Buchari,1977. Epigrafi dan Sejarah Indonesia, Majalah arkeologi No. I, Fakultas Sastra, Universitas Indonesa, Jakarta.

De Graaf, HJ. dan Th.G.Th. Pigeaud,1985.Kerajaan-Kerajaan Islam di Jawa, Grafiti Pers, Jakarta.

Fatimi, S.Q,1963.Islam Come To Malaysia, SMSRI, Singapura.

Hill, A. H.1960. Hikayat Raja-Raja Pasai, JMBRAS, 33, (2).

Ma'luf Louis, 1973. Al-Munjid Fi al-Lughah, Beirut, Dar al-Fikr.

Marsden,William,1975. The History of Sumatra Oxford University Press Kuala Lumpur.

Mujib,1992.Niat Sebagai Indikasi Keberhasilan Langkah Bidang Kemasjidan, Yayasan Masjid, al-Ikhlas, Jakarta, (tidak diterbitkan).

Munsi,Abdullah bin Abdul Kadir,1952.Sejarah Melayu, (penyunting A. Teew), Jambatan, Jakarta.

Sabiq, Syekh,1983.Sayyid, Fiqh Sunnah III, Beirut, Dar al-Fikr.

Soekmono, R.1994.Sejarah Kebudayaan Indonesia 3, Kanisius, Yogyakarta.

Santosa, Halina Budi,1993.Nisan-Nisan Samodera Pasai, Direktorat Jendral Kebudayaan, Proyek Media Pengembangan Kebudayaan, Jakarta.

Tjandrasasmita,Uka,1976.Sejarah Nasional Indonesia III, (Editor), Departe-men Pendidikan dan Kebudayaan, Jakarta, 1976. 
1986. Sepintas Mengenai Peninggalan Kepurbakalaan Islam di Pesisir Utara Jawa,Aspek Aspek Arkeologi Indonesia, no. 3, Pusat Penelitian Arkeologi Nasional, Jakarta.

1992. Riwayat Penyelidikan Kepurbakalaan Islam di Indonesia, 50 Tahun Lembaga Purbakala dan Peninggalan Sejarah, Pusat Penelitian Arkeologi Nasional, Jakarta. 